\title{
PRIORIZAÇÃo DOS CRITÉRIOS COMPETITIVOS DAS OPERAÇÕES BASEADO NOS RECURSOS ESTRATÉGICOS
}

\section{RESUMO}

Na literatura da área de estratégia de operações, os critérios competitivos devem ser priorizados tendo como referência a sua importância para os clientes. Nesse sentido, foi realizada a revisão da literatura sobre os temas análise estratégica de operações e teoria baseada em recursos, visando um melhor entendimento de como os recursos estratégicos se associam aos critérios competitivos. Dessa revisão, foi proposto um framework de análise, pré-testado em duas empresas de Canoas-RS. Durante essa etapa realizou-se observações diretas nas empresas, além de entrevistas. Os resultados mostram que um recurso específico pode contribuir para vários critérios competitivos, não havendo uma relação específica entre um recurso estratégico e um critério competitivo em particular.

Palavras-chaves: Estratégia; Competitividade; Recursos Estratégicos; Prioridades Competitivas, Operações; Agronegócios.

\section{ABSTRACT}

In the strategic operation area, competitive criteria must be prioritized focusing on the client importance. In this sense, a literature review was made on the themes strategic operation analysis and theory based on resources, aiming at contributing to the understanding of associations between strategic resources and competitive criteria. A framework was proposed based on this analysis. This framework was tested in two companies at Canoas, Rio Grande do Sul, Brazil. During this stage, direct observations and interviews were promoted in both companies. The results demonstrate that a specific resource can contribute for several competitive criteria, and that there is no specific relationship between a strategic resource and a competitive criterion.

Key words: Strategy; Competitiveness; Strategic Resources; Competitive Priorities; Operations; Agribusiness.
Tania Nunes da Silva $P P G A / E A / U F R G S$

Mestrado pela FEA/USP,

Doutorado pela Sociologia/USP tnsilva@ea.ufrgs.br

Marcelo Fernandes Pacheco

Dias

Universidade Federal de Pelotas UFPEL

Doutorado em Agronegócios pela UFRGS

mfpdias@hotmail.com

Silvio Santos Junior

Doutorado em Agronegócios pela UFRGS

Professor e Pesquisador da Unoesc silviosantos.junior@unoesc.br

Nadir Paula da Rosa Instituto Federal Catarinenses Campus Videira Graduação em Administração com Habilitação em Comércio Exterior-

UNOESC

Mestrado em Agronegócios UFRGS nadirpr@gmail.com

Érica Silva Mendonça Doutoranda na Escola de Engenharia de São Carlos - USP Mestrado em Agronegócios pela UFRGS

Recebido em 21/setembro/2009 Aprovado em 17/junho/2011 


\section{INTRODUÇÃO}

O processo da área de estratégia de operações tem sido aprimorado sistematicamente nos últimos anos. Entretanto, novos avanços fazem-se necessários, principalmente pelos conhecimentos desenvolvidos contemporaneamente na abordagem da estratégia baseada em recursos.

Um avanço necessário diz respeito ao processo de escolha dos critérios competitivos para cada unidade de negócio, decisão inicial para a elaboração da estratégia de operações. Critérios competitivos são definidos como um conjunto consistente de prioridades ou fatores competitivos que a empresa tem de valorizar para ter sucesso (BARROS NETO e FENSTERSEIFER, 2000). A escolha dos critérios competitivos deve ser feita considerando as necessidades dos clientes; os trade-offs existentes entre os critérios competitivos; o desempenho da empresa nesses critérios em relação à concorrência; os recursos estratégicos que a empresa possui ou aos quais pode ter acesso. Recursos Estratégicos são definidos como aqueles recursos que podem conferir à organização capacidade de sustentar vantagem competitiva (BARNEY, 2001).

Entretanto, existe uma lacuna na literatura de operações para essa definição, que é como priorizar os critérios competitivos em que a empresa deseja incrementar a vantagem ou recuperar a defasagem sobre os concorrentes, considerando os recursos estratégicos a que ela possa ter acesso. A compreensão dessa questão pode propiciar também um maior entendimento de como os recursos se associam aos diversos critérios competitivos para um desempenho superior. Nesse sentido, foi realizada uma revisão da literatura sobre os assuntos análise estratégica de operações e teoria baseada em recursos. Dessa revisão, foi proposto um framework de análise, o qual foi pré-testado.

Aaplicaçãodo framewok foirealizada em duas grandes empresas no Estado do Rio Grande do Sul. Os resultados foram analisados qualitativa e quantitativamente.

Este texto está organizado da seguinte forma: na seção 2 são apresentados os fundamentos sobre avaliação da importância e do desempenho dos critérios competitivos; na seção 3 é apontado o esteio teórico sobre identificação dos recursos estratégicos; na seção 4 é discutida a relação entre recursos estratégicos e critérios competitivos; na seção 5 é mostrado o framework proposto para priorização dos critérios competitivos; na seção 6 é apresentado o método de pesquisa; na seção 7 são indicados os resultados; na seção 8 são citadas as considerações finais, seguidas da bibliografia.

\section{AVALIAÇÃO DA IMPORTÂNCIA E DO DESEMPENHO DOS CRITÉRIOS COMPETITIVOS}

Existem, na literatura, várias definições para o termo estratégia de operações. Uma das mais aceitas foi proposta por Wheelwright (1984), que aborda o tema de estratégia procurando definir o elo entre a estratégia de negócio e a estratégia de operações, na linha proposta originalmente por Skinner (1969). O autor define estratégia de operações como um padrão de decisões ao longo do tempo, que irá permitir à unidade de negócio atingir uma desejada vantagem competitiva. Alguns autores conceituam estratégia de operações de forma um pouco diferente, porém dentro do mesmo princípio básico colocado originalmente por Skinner (1969) e Wheelwright (1984), ou seja, com base no fato de que as operações dão suporte à estratégia de negócio da empresa. A formulação da estratégia de operações inicia-se, portanto, pela definição da estratégia de negócios nos diferentes segmentos de mercado em que a empresa atua.

Os principais elementos que estabelecem o significado do conteúdo de uma estratégia de operações são os critérios competitivos, relacionados com a estratégia de negócio da empresa, e as categorias ou áreas de decisão, relativas às políticas adotadas pela função produção e operações das empresas (PIRES, 1995).

Segundo Slack (2002) os critérios competitivos mencionados na literatura de estratégia de operações são praticamente os mesmos: custo, qualidade, flexibilidade, velocidade e confiabilidade de entrega.

O critério qualidade pode ser dividido em performance, características secundárias, confiabilidade, conformidade, durabilidade serviços agregados, estética e qualidade percebida. O critério flexibilidade pode ser dividido em flexibilidade de mix de produtos, flexibilidade de novos produtos, flexibilidade de volume, flexibilidade de entrega (PAIVA, CARVALHO Jr. E FENSTERSEIFER, 2004).

Para a identificação da importância de cada um dos 
critérios, Slack (2002) desenvolveu uma escala de 9 pontos. No extremo superior (1), o critério proporciona uma vantagem crucial sobre os clientes e é o principal impulso da competitividade. No extremo inferior (9), o critério nunca é considerado pelos clientes e provavelmente nunca o será. Slack (2002) sugere ainda distinguir critérios ganhadores de pedidos e critérios qualificadores. Hill (1994) define critérios ganhadores de pedidos como os mais importantes na decisão de fazer negócios com a empresa; são, portanto, os fatoreschaves da competitividade. Já os critérios qualificadores são aspectos da competitividade que apenas credenciam a empresa a ser uma possível fornecedora; para esses critérios, empresas com um desempenho abaixo do nível considerado “qualificador" sequer serão cogitadas para a realização de negócios. Os critérios avaliados com importância de 1 a 3 na escala de Slack são considerados ganhadores de pedido; os avaliados de 4 a 6 são os critérios qualificadores; e os avaliados de 7 a 9 são considerados menos importantes, mas são incluídos na análise, pois podem tornar-se importantes no futuro.

Assim como para a análise da importância dos critérios competitivos, Slack (2002) também propôs uma escala de novepontos paraaidentificaçãododesempenhodasoperações nesses critérios. No extremo superior (1), o desempenho das operações é consistente e consideravelmente melhor do que o do concorrente mais próximo; no extremo inferior (9), o desempenho das operações é consistentemente pior do que o da maioria dos concorrentes.

Parapoderfazerumaavaliação,Slack(2002)desenvolveu uma matriz que relaciona os critérios competitivos com o desempenho de um sistema de produção, em comparação com os concorrentes. No eixo horizontal, encontram-se as escalas de valores do cliente; no eixo vertical está a escala de desempenho do sistema, comparativamente à concorrência.

Nessa matriz, chamada importância-desempenho, o autor define quatro zonas distintas: zona apropriada, de melhoramento, de ação urgente, e de excesso. A zona apropriada é aquela em que a empresa deveria focalizar suas operações. Abaixo dessa zona, há um comprometimento com o desempenho, comparativamente aos concorrentes, o que poderia prejudicar a sobrevivência da empresa no longo prazo. Critérios que estejam na zona de melhoramento devem ser analisados, a fim de identificar possíveis ações de melhorias que possam levá-los à zona apropriada. A zona de ação urgente contém os critérios que são ganhadores de pedidos, porém o desempenho da empresa está muito abaixo do desempenho da concorrência. Há, portanto, necessidade de ações corretivas substanciais e urgentes que levem a empresa e seus produtos a responder melhor às necessidades dos clientes. Para os critérios localizados na zona de excesso, a empresa apresenta um desempenho superior, porém os clientes não os consideram relevantes na decisão de compra, ou seja, a empresa está colocando excesso de recursos em critérios que não trazem resultados positivos.

Para os critérios competitivos situados na zona de excesso, Slack (2002) destaca duas ações possíveis para essa situação. Primeiro, via esforços de marketing, induzir o cliente a ver esse critério como importante e passar a valorizá-lo na hora da compra; segundo, realocar os recursos das operações que estão sendo usados para sustentar esse desempenho superior para outros critérios mais valorizados pelo cliente.

O segundo elemento do conteúdo da estratégia de operações são as categorias de decisão. Entretanto, Paiva, Carvalho Jr. e Fensterseifer (2004) afirmam que essa classificação clássica da literatura de estratégias de operações não oferece indicações de como buscar coerência interna, quando a empresa busca desenvolver objetivos comuns e não conflitantes para a organização. Eles propõem utilizar o conceito de atividades inter-relacionadas na Rede de Valor de Operações (RVO), com o objetivo de agregar valor para o cliente, integrar as atividades da RVO e buscar contínua adequação entre as atividades existentes. A Rede de Valor das operações é composta pelas atividades de Produção, Distribuição, Desenvolvimento de Produtos, Suprimentos e Serviços Agregados que estão ligadas entre si e que devem interagir segundo as escolhas estratégicas da organização.

\section{IDENTIFICAÇÃO DOS RECURSOS ESTRATÉGICOS}

A abordagem conhecida como Visão da Firma Baseada em Recursos enfatiza que a captura de ganhos superiores ocorre com base nos recursos e nas competências internas da empresa.

Grant (1991) propõe a classificação dos recursos em categorias como ponto de partida para a identificação dos recursos estratégicos. Segundo o autor, as seis categorias mais sugeridas são: recursos financeiros, recursos físicos, recursos humanos, recursos tecnológicos, reputação e recursos organizacionais.

Fensterseifer e Wilk (2005) revisaram os estudiosos 
da área de recursos sobre as características que deve ter um recurso estratégico. Concluíram que para um recurso possibilitar uma vantagem competitiva deve ter uma ou mais das seguintes características: complementaridade, dependência de caminho, escassez, grau de codificação do conhecimento, ambiguidade causal e condição de negociabilidade. Descreve-se a seguir esses conceitos:

- Complementaridade: ocorre quando determinados conjuntos de recursos só produzem valor no momento em que são utilizados em conjunto, pelo efeito sinérgico da atuação conjunta;

- Dependência de Caminho: implica em um recurso em função de aprendizado singular desenvolvido ao longo do tempo;

- Condição de Escassez: significa a posse de um recurso raro, ou escasso em relação à demanda por seus serviços;

- Grau de Codificação do Conhecimento: relacionado a interações entre pessoas, grupos e funções de difícil imitação;

- Ambiguidade Causal: a ambiguidade causal implica a dificuldade de rastrear, com base numa posição competitiva, qual o recurso que sustenta aquela posição;

- Condição de Negociabilidade: determinados recursos estão configurados de tal forma que se torna difícil, tanto para o vendedor quanto para o comprador, analisá-los e determinar-lhes o custo e o valor.

\section{RELAÇÃO DOS RECURSOS ESTRATÉGICOS COM OS CRITÉRIOS COMPETITIVOS}

Paiva, Carvalho Jr. e Fensterseifer (2004 p.76) apresentam três conceitos para explicar a relação entre recursos estratégicos e critérios competitivos: o conceito de recursos, de competências de operações e de competências da empresa.

O conceito de recursos pode ser entendido como ativos, informações, e conhecimento controlados pela empresa que a tornam capaz de conceber e implementar estratégias que melhorem sua competitividade. As competências de operações constituem o resultado de uma seleção, integração, balanceamento, alocação e utilização de recursos dentro da RVO de tal forma adequada que as atividades sejam realizadas com eficiência e eficácia. As competências da empresa são aquelas perceptíveis aos clientes e construídas a partir da combinação das competências de operações geradas a partir do uso criativo e inovador de seus diferentes recursos.

Com base nesses conceitos, foi elaborada a Figura 1. Na região central da figura encontram-se os recursos estratégicos. Estão ali representados como fonte primária das vantagens competitivas. As setas mais largas e mais estreitas, apontadas para todas as direções indicam que os recursos estratégicos estarão atuando sobre toda a rede de valor das operações, entretanto em graus de intensidade diferenciados. Se os recursos estiverem sendo bem selecionados, alocados e utilizados dentro da RVO, o resultado dessa combinação criará na empresa determinadas competências de operações que poderão ser percebidas pelos clientes como diferenciais competitivos em cada um dos critérios competitivos (competências da empresa).

Figura 1 - Associação entre recursos estratégicos e critérios competitivos

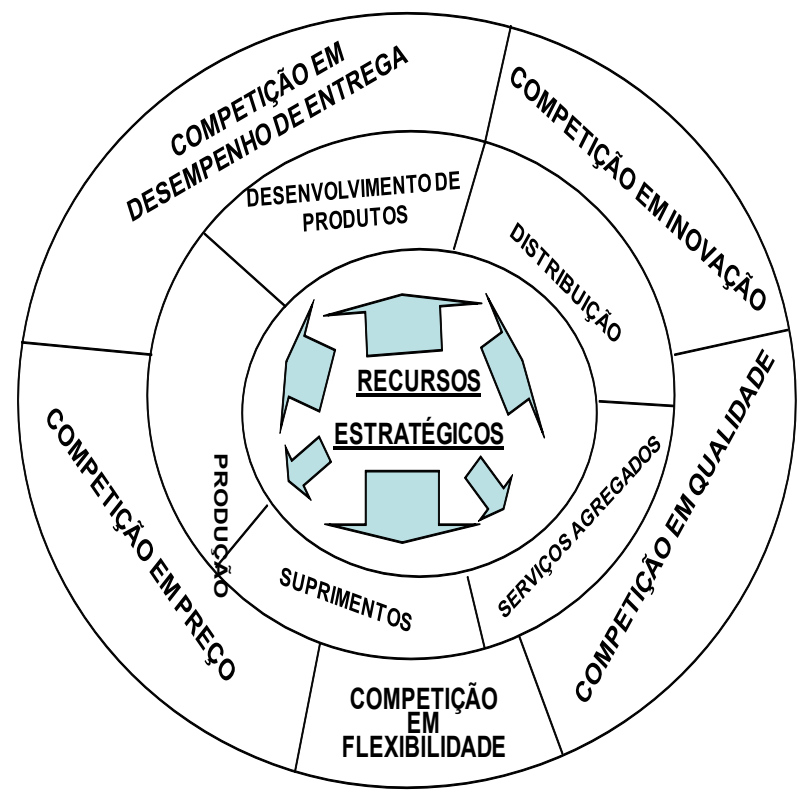

Fonte: Baseado em Paiva, Carvalho Jr. e Fensterseifer (2004, p.76).

\section{PRIORIZAÇÃO DOS CRITÉRIOS COMPETITIVOS}

A contribuição deste artigo diz respeito a como escolher os critérios competitivos levando-se em consideração, também, os recursos estratégicos. Com base na revisão da literatura foi proposto um framework, 
representado na figura 2.

A Etapa 1 do framework consiste na determinação dos critérios competitivos e na avaliação da importância e do desempenho para cada critério, de acordo com o modelo proposto por Slack (2002). A intenção é classificar os critérios competitivos, segundo a importância dada pelo mercado, e avaliar o desempenho da empresa ante a concorrência, com a finalidade de compreender as competências empresariais reconhecidas e as não reconhecidas pelo mercado. Os critérios são classificados em "Critérios Ganhadores de Pedidos e Qualificadores na Zona Apropriada" (Etapa 1.1), "Critérios Ganhadores de Pedidos e Qualificadores nas Zonas de Melhoramento e de Ação Urgente" (Etapa 1.2), e "Critérios Menos Importantes" (Etapa 1.3).

A Etapa 2 consiste na identificação dos recursos estratégicos que a empresa possui, segundo as características propostas por Fensterseifer e Wilk (2005).

A Etapa 3 compreende uma matriz que relaciona os recursos estratégicos com os critérios competitivos, com o intuito de identificar se há recursos estratégicos e quais podem ser selecionados para um balanceamento e integração melhor com a RVO, para o aumento do desempenho da empresa nas competências mais valorizadas pelo mercado. Para a construção dessa matriz, abstraiu-se da proposta de relacionamento entre produtos e recursos, proposta por Wernerfelt (1984).

A Etapa 4 consiste na seleção dos critérios competitivos ganhadores de pedidos e classificadores, com baixo desempenho e que tenham contribuição positiva com os recursos. A Etapa 5 consiste em rever os recursos estratégicos para aumentar o desempenho nos critérios competitivos escolhidos na fase anterior e na reavaliação da rede de valor das operações (Etapa 5.1). A Etapa 6 consiste na priorização final dos critérios competitivos pela seleção dos critérios ganhadores de pedidos e qualificadores que estão na zona apropriada (Etapa 1.1), mais os critérios ganhadores de pedidos e qualificadores que estão na zona de ação urgente e de melhoramento, porém com positiva associação com os recursos estratégicos (Etapa 5.1).

A decisão dos critérios competitivos que não serão selecionados pela organização consta da etapa 8. São compostos pelos critérios menos importantes (Etapa 1.3) e pelos critérios ganhadores de pedidos ou qualificadores de baixo desempenho e com pouca ou sem associação

Figura 2 - Seleção das prioridades competitivas das operações baseada nos recursos estratégicos

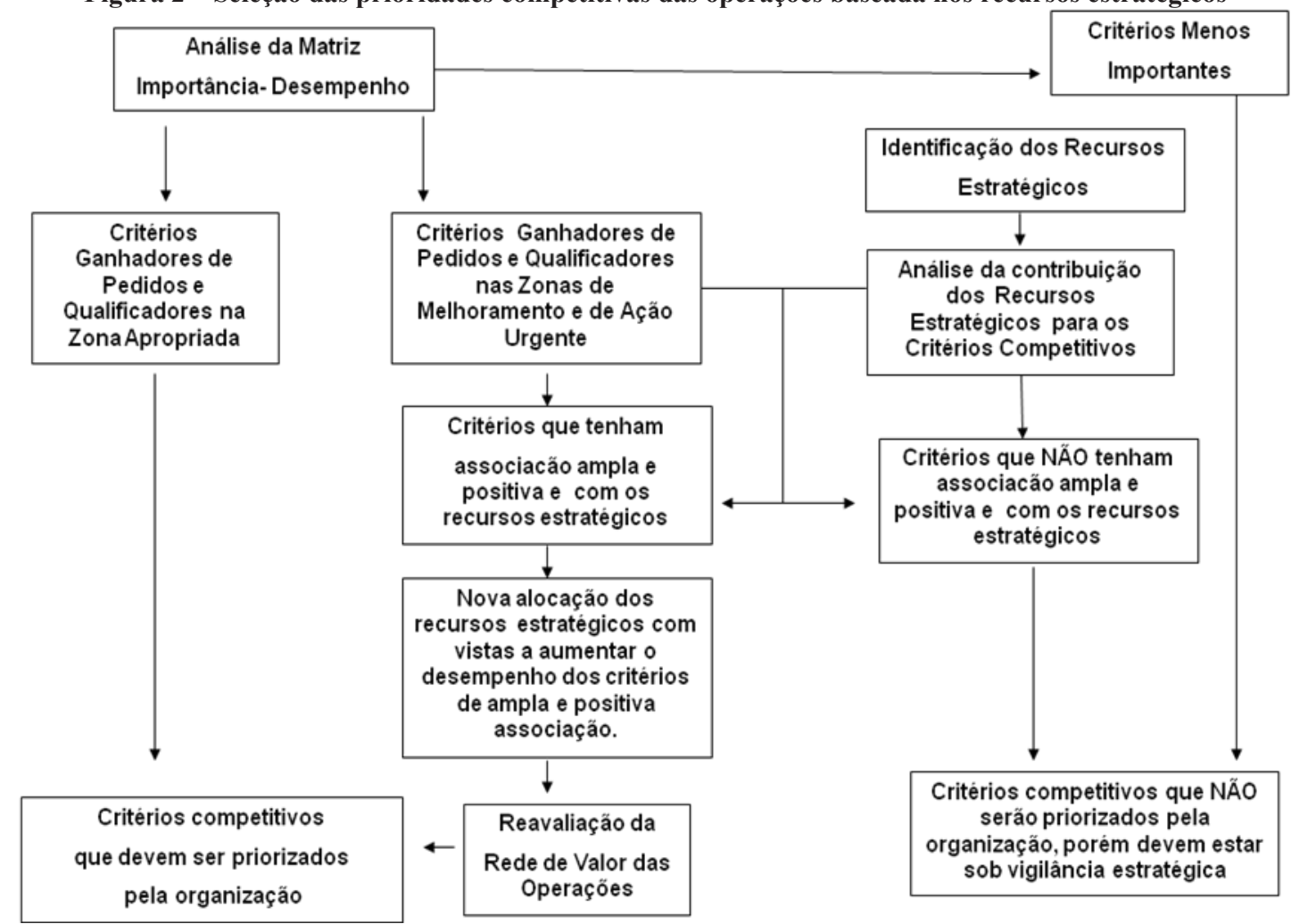

Fonte: Baseada em Slack (2002), Paiva, Carvalho Jr. e Fensterseifer (2004), Wernerfelt (1984). 
(Etapa 7). Caso a empresa entenda que possa mudar a percepção do mercado, via esforços de marketing ou por tratar-se de uma tendência de futuro, poderá alocar alguns desses critérios, para as etapas 1.1 e 1.2, conforme a posição na matriz importância-desempenho e reavaliar a decisão, de acordo com a sequência proposta. Em relação aos critérios de ganhadores de pedidos ou qualificadores de baixo desempenho e com pouca ou sem associação com os recursos estratégicos (Etapa 7), a empresa poderá desenvolver ou adquirir recursos estratégicos para melhorar o desempenho, e então, alocá-los na etapa 5 ou decidir não competir nesse critério (Etapa 8).

\section{MÉTODO}

O objetivo da pesquisa é verificar como os critérios competitivos e as operações podem ser priorizados levando em consideração os recursos estratégicos da empresa e os interesses do mercado. Dessa forma, a pesquisa prevê a análise da matriz importância-desempenho, a identificação dos recursos estratégicos e a verificação de como se dá o relacionamento desses recursos com os critérios competitivos, com o fim de subsidiar a escolha de um conjunto de critérios com os quais a empresa poderá competir.

Nesse sentido, foi realizada uma pesquisa exploratória nas empresas Tecno Moageira S.A. e AGCO do Brasil S.A., unidade Canoas-RS. Essa pesquisa foi classificada como exploratória, pois teve por objetivo prover a compreensão do problema enfrentado pelo pesquisador e avaliar o framework proposto. Esse tipo de pesquisa se caracteriza por flexibilidade e versatilidade com relação aos métodos (MALHOTRA, 2001).

Para a coleta de dados, foi realizada uma visita nas empresas nas quais se realizou observação direta e entrevistas semiestruturadas, com o objetivo de caracterizar os negócios, adaptar os critérios existentes na literatura, e identificar os recursos estratégicos de cada empresa pesquisada. As análises desses dados foram feitas pelo método da análise de conteúdo.

Após essa etapa, foi realizada nova coleta de dados pelo envio de e-mail de dois questionários estruturados: um para a identificação da importância dos critérios e outro para a verificação do desempenho das empresas nesses critérios. A pergunta que orientou a resposta do questionário de importância foi: De acordo com a escala de importância abaixo, assinale com um "X" o seu julgamento do GRAU DE IMPORTÂNCIA desses critérios competitivos para o mercado. Para a análise do desempenho, a questão que orientou a resposta do questionário foi: De acordo com a escala de desempenho abaixo, assinale com um " $X$ " o seu julgamento do GRAU DE DESEMPENHO desses critérios competitivos da sua empresa, comparativamente à concorrência.

Nessa mesma etapa, foi solicitada também a associação entre os critérios competitivos e os recursos estratégicos por meio da resposta de uma matriz de dupla entrada (Tabelas 1 e 2), em que os entrevistados responderam entre -2 (muita contribuição negativa), -1 (pouca contribuição negativa), 0 (neutro), 1 (pouca contribuição positiva) e 2 (muita contribuição positiva). A questão que orientou a resposta da tabela foi: numere de -2 a 2, de acordo com a escala abaixo, quanto cada recurso contribui para o desempenho dos critérios competitivos.

Respondeu os questionários um gerente comercial de cada empresa. A análise dos dados de importânciadesempenho foi realizada com base em Slack (2002) e a relação dos recursos com os critérios competitivos em Wernerfelt (1984).

\section{RESULTADOS}

Inicialmente será realizada a caracterização da empresa e em seguida serão apresentados e discutidos os resultados segundo o framework (Figura 2) proposto para determinação dos critérios competitivos.

\subsection{TECNO MOAGEIRA S.A.}

A Tecno Moageira S.A. foi fundada em 1966 em Porto Alegre - RS, com capital social 100\% nacional, até hoje presidida por um dos fundadores, Sr. Heinz Friedrich Elter. A empresa teve como objetivo inicial a produção de máquinas e equipamentos para moinhos e silos de cereais. Hoje com a experiência acumulada em mais de 40 anos, na busca de soluções para as necessidades específicas de cada cliente, com permanente atendimento e atualização tecnológica, a empresa tem sido requisitada a participar de projetos/fornecimento de equipamentos em regime de turn-key ou parcial para todo o território nacional, inclusive para os países do Mercosul. Os mercados nos 
quais atua são: agroindústria, petroquímica, indústria de celulose, termoelétrica a carvão, usinas siderúrgicas, mineradoras e cimenteiras, terminais portuários, fertilizantes. Recentemente, com o intuito de atender às necessidades e expectativas dos clientes, colaboradores, acionistas e comunidade, com inovações e melhoria contínua dos processos, produtos e serviços, a empresa conquistou o Certificado ISO 9001:2000.

\subsubsection{Análise da matriz} importância - desempenho

\section{Tecno Moageira S.A.}

Nesta subseção são analisados a importância e o desempenho de cada um dos critérios competitivos, por intermédio da matriz importância-desempenho (Figura 3), com a finalidade de compreender as competências empresariais reconhecidas pelo mercado e quais precisam ser aprimoradas pela Tecno Moageira. Corresponde à Etapa 1 do framework proposto.

Constata-se que na zona apropriada encontramse os critérios competitivos "ganhadores de pedido": confiabilidade, conformidade, conformidade de entrega, marca, e desempenho do produto. Esses são os critérios chaves para a competitividade da empresa, pois são os mais importantes na decisão de fazer negócios (Hill, 1994). $\mathrm{Na}$ mesma zona, encontram-se os critérios competitivos "qualificadores": durabilidade, estética do produto, e flexibilidade do produto, considerados importantes também, pois qualificam a empresa como potencial fornecedora (Hill, 1994). Analisando o framework proposto, etapa 1.1, estes são os critérios que devem priorizados pela empresa.

Dentro da zona de melhoramento encontram-se os seguintes critérios "ganhadores de pedido": prazo de pagamento e assistência pré-venda. Na zona de ação urgente estão os critérios "ganhadores de pedido": custo e velocidade de entrega; e também o critério qualificador: assistência pós-venda.
Todos esses critérios competitivos são importantes para o negócio; porém, a empresa não tem competência empresarial diferenciada reconhecida pelo mercado, pois, na visão do cliente, ela possui no máximo desempenho igual ao da concorrência (Slack, 2002). Segundo o framework proposto (Figura 2), etapa 1.2, estes são os critérios pelos quais a empresa deverá avaliar seus recursos, com o objetivo de identificar as possibilidades de conseguir uma vantagem competitiva.

Os critérios competitivos considerados "menos importantes" foram: flexibilidade de volume, inovação, e características secundárias. São aspectos pouco valorizados pelos clientes na hora de fazer os negócios (Hill, 1994). São os critérios que, por serem considerados menos importantes (Etapa 1.3) no mercado, não serão escolhidos como prioridades competitivas (Etapa 8).

\subsubsection{Identificação dos recursos estratégicos da Tecno Moageira S.A.}

Os recursos estratégicos identificados são apresentados no Quadro 1. Abaixo são caracterizados cada um desses recursos identificados.

A empresa tem como recursos estratégicos sistemas de engenharia modernos e sofisticados que se complementam o conhecimento e experiência dos engenheiros, possibilitando à empresa atender o mercado 
com flexibilidade dando solução aos problemas de engenharia demandados pelos clientes, o que contribui para a confiabilidade e conformidade e durabilidade dos produtos.

O recurso de direção empreendedora reforça na empresa, com exemplos desde a fundação, a visão de aceitar desafios, desenvolver novos produtos e mercados, orientar para soluções customizadas, inovar sempre que possível e antecipar-se ao mercado.

Quadro 1. Lista dos recursos estratégicos identificados na Tecno Moageira S.A.

\begin{tabular}{|c|c|c|}
\hline RECURSOS & $\begin{array}{l}\text { FATOR DE SUSTENTAÇÃO } \\
\text { ESTRATÉGICA }\end{array}$ & $\begin{array}{l}\text { TIPOS DE } \\
\text { RECURSOS }\end{array}$ \\
\hline Direção empreendedora & $\begin{array}{l}\text { Grau de codificação do } \\
\text { conhecimento. }\end{array}$ & Recursos humanos \\
\hline Sistemas de engenharia & Complementaridade & $\begin{array}{c}\text { Tecnológico, } \\
\text { humanos }\end{array}$ \\
\hline $\begin{array}{l}\text { Conhecimento e experiência } \\
\text { dos enoenheiros }\end{array}$ & $\begin{array}{l}\text { Grau de codificação do } \\
\text { conhecimento }\end{array}$ & Humanos \\
\hline $\begin{array}{l}\text { Sinergia entre empresas do } \\
\text { grupo }\end{array}$ & Complementaridade & Organizacional \\
\hline Pesquisa e desenvolvimento & $\begin{array}{l}\text { Grau de codificação do } \\
\text { conhecimento } \\
\text { e dependência de caminho }\end{array}$ & $\begin{array}{l}\text { Humanos, } \\
\text { tecnológicos }\end{array}$ \\
\hline
\end{tabular}

Fonte: Elaborado pelos autores.

O recurso sinergia entre as empresas do grupo contribui principalmente para os critérios de serviços agregados na assistência pré e pós vendas, marca, flexibilidade de produtos e inovação, pois possuem atividades complementares de comercialização, importação e exportação de máquinas para os mercadosalvo da Tecno Moageira.

O setor de pesquisa e desenvolvimento atua em sinergia com o setor de engenharia e fabricação, na busca de soluções inovativas aos problemas de engenharia e no aprimoramento dos critérios da qualidade.

\subsubsection{Associação dos recursos estratégicos com os} critérios competitivos da Tecno Moageira S.A.

O objetivo desta análise é verificar os critérios e se seus critérios competitivos que precisam ser aprimorados possuem recursos estratégicos que possam subsidiar essa melhoria. A matriz de relacionamento utilizada foi abstraída de Wernerfelt (1984).

Analisando a linha "soma das contribuições positivas " na Tabela 1 constata-se que os recursos estratégicos podem contribuir para a melhoria do desempenho de todos os critérios "ganhadores de pedidos", que se encontram nas zonas de melhoramento e nas zonas de ação urgente.

A mesma constatação é válida para o critério competitivo "qualificadores" (assistência pós-venda), que se encontra na zona de ação urgente, pois em todas há recursos estratégicos que podem contribuir para um aprimoramento do desempenho.

Analisando a possibilidade de a empresa

Tabela 1. Associação dos recursos estratégicos com os critérios competitivos da Tecno Moageira S.A.

\begin{tabular}{|c|c|c|c|c|c|}
\hline \multirow[b]{3}{*}{ RECURSOS } & \multicolumn{2}{|c|}{ Ganhadores de Pedidos } & \multirow{2}{*}{\multicolumn{3}{|c|}{$\frac{\text { Qualificadores }}{\text { Zona de Ação Urgente }}$}} \\
\hline & \multirow{2}{*}{\begin{tabular}{|c|}
$\begin{array}{l}\text { Zona de } \\
\text { Melhoramento }\end{array}$ \\
$\begin{array}{c}\text { Assistência Pré- } \\
\text { Venda }\end{array}$ \\
\end{tabular}} & \multirow{2}{*}{\begin{tabular}{|c|}
$\begin{array}{c}\text { Zona de } \\
\text { Ação } \\
\text { Urgente }\end{array}$ \\
Menor custo \\
\end{tabular}} & & & \\
\hline & & & $\begin{array}{l}\text { Velocidade } \\
\text { de entrega }\end{array}$ & $\begin{array}{l}\text { Menor prazo } \\
\text { de Pagamento }\end{array}$ & $\begin{array}{l}\text { Assistência } \\
\text { Pós-Venda }\end{array}$ \\
\hline Direção empreendedora & 1 & 1 & 2 & 1 & 1 \\
\hline Sistemas de engenharia & 1 & 1 & 1 & 1 & 1 \\
\hline $\begin{array}{l}\text { Conhecimento e experiência } \\
\text { nos recursos humanos de } \\
\text { engenharia }\end{array}$ & 1 & -1 & 1 & 1 & 1 \\
\hline $\begin{array}{l}\text { Sinergia entre empresas do } \\
\text { grupo }\end{array}$ & 1 & & & & 1 \\
\hline Pesquisa e desenvolvimento & 2 & 2 & & & \\
\hline $\begin{array}{l}\text { Soma das contribuições } \\
\text { Positivas }\end{array}$ & 6 & 4 & 4 & 3 & 4 \\
\hline $\begin{array}{l}\text { Soma das contribuições } \\
\text { Negativas }\end{array}$ & 0 & -1 & 0 & 0 & 0 \\
\hline
\end{tabular}

Fonte: Elaborada pelos autores. 
competir em preço, constata-se um trade-off, pois o recurso conhecimento experiência dos recursos humanos de engenharia, tanto contribui para o aprimoramento dos demais critérios competitivos, quanto prejudica o critério competitivo "menor custo".

Para que os recursos estratégicos sustentem uma vantagem nesses critérios competitivos, será necessário rever a alocação e a combinação desses recursos dentro da RVO da empresa.

\section{$7.2 A G C O$}

A AGCO foi fundada nos Estados Unidos em 1990, com sede em Duluth, Geórgia, EUA. Atualmente conta com 23 fábricas no mundo, detém $1 / 4$ da produção e comercialização de máquinas e produtos agrícolas, uma rede de concessionários e distribuidores presentes em mais de 140 países. Sua estratégia global inclui expansão na Europa Ocidental e mercados emergentes da Europa Central e Oriental e China, objetivando manter sua posição de líder no setor de equipamentos agrícolas. Suas principais marcas são Massey Ferguson, Fendt, Challenger e Valtra. Suas três unidades fabris no Brasil estão situadas em Canoas e Santa Rosa (Rio Grande do Sul), que exportam para cinco continentes; e em Mogi das Cruzes (São Paulo).

\subsubsection{Análise da matriz importância- desempenho AGCO do Brasil S.A. Canoas}

Com o mesmo
propósito da anális
feita para a empresa
Tecno Moageira S.A
nesta subseção fo
analisada a importância e o desempenho de cada um dos critérios competitivos da AGCO do Brasil - Unidade de Canoas.

$\mathrm{Na}$ zona apropriada encontram-se os critérios "ganhadores de pedidos" marca, durabilidade e assistência pós-venda (Figura 4). Analisando o framework proposto

Fonte: Elaborada pelos autores.
(Figura 2), etapa 1.1, estas são os critérios que devem ser priorizados pela empresa.

Dentro da zona de melhoramento encontram-se os critérios "ganhadores de pedidos": desempenho do produto, confiabilidade, custo e conformidade e na zona de ação urgente, inovação e estética do produto (Etapa 1.2 do framework). Sobre os "critérios qualificadores", encontramse na zona de melhoramento: assistência pré-venda, prazo de pagamento, velocidade e confiabilidade de entrega. Por serem critérios importantes para a competitividade da empresa, porém com desempenho igual ou menor do que o da concorrência (Slack, 2002), estes critérios devem ser analisadas sobre o potencial de contribuição dos recursos estratégicos, com vistas ao aprimoramento do desempenho (Etapa 3 do framework).

O critério competitivo considerado "menos importante" foi flexibilidade de volume (Etapa 1.3 do framework), critério pouco valorizado pelos clientes e que não será priorizado (Etapa 8), porém a empresa poderá rever essa decisão caso entenda que possa mudar a percepção de mercado ou que esse critério venha a ser valorizado pelos clientes no futuro.

Figura 4. Matriz importância-desempenho da AGCO do Brasil- Canoa

Matriz Importância - Desempenho AGCO

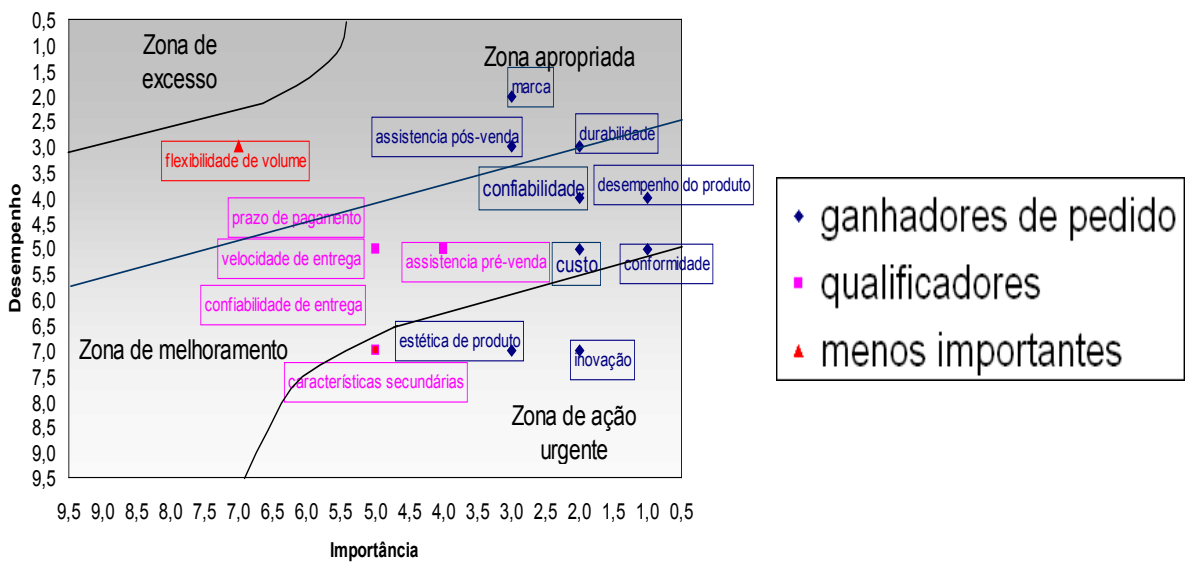

\subsubsection{Identificação dos recursos estratégicos da AGCO} do Brasil S.A. - Canoas

Os recursos estratégicos são apresentados no Quadro 2. São caracterizados, abaixo, cada um desses recursos.

Caracteriza-se a transferência de tecnologia entre 
as unidades como o compartilhamento de tecnologias entre as diversas unidades da empresa , o qual possibilita a inovação principalmente nos critérios durabilidade, conformidade, confiabilidade e desempenho do produto. que se encontra na zona de ação urgente e na zona de melhoramento, pois em todas há recursos estratégicos que podem contribuir para um aprimoramento do desempenho.

Quadro 2. Lista dos recursos estratégicos da AGCO do Brasil S.A.

\begin{tabular}{|c|c|c|}
\hline RECURSOS & $\begin{array}{c}\text { FATOR DE SUSTENTAÇÃO } \\
\text { ESTRATÉGICA }\end{array}$ & $\begin{array}{c}\text { TIPOS DE } \\
\text { RECURSOS }\end{array}$ \\
\hline $\begin{array}{c}\text { Transferência de tecnologia entre as } \\
\text { unidades }\end{array}$ & Dependência de caminho & $\begin{array}{l}\text { Humanos } \\
\text { Organizacionais }\end{array}$ \\
\hline Sistema de controle de qualidade & Dependência de caminho & Organizacionais \\
\hline $\begin{array}{l}\text { Centro de pesquisa para desenvolvimento } \\
\text { com campo de teste }\end{array}$ & Dependência de caminho & $\begin{array}{c}\text { Humanos/ } \\
\text { Tecnológicos }\end{array}$ \\
\hline $\begin{array}{c}\text { Tempero do aço parả a produção dos eixos } \\
\text { dos tratores }\end{array}$ & Condição de negociabilidade & Tecnológico \\
\hline Logística Integrada & $\begin{array}{l}\text { Grau de codificação do conhecimento e } \\
\text { complementaridade }\end{array}$ & Organizacionais \\
\hline
\end{tabular}

Fonte: Elaborado pelos autores.

Sistema de controle de qualidade são os programas que a empresa desenvolve com o propósito de melhorar os critérios da qualidade, como por exemplos, as certificações ISO 14001:1996, OHSAS 18001, e ISO 9001:2000.

Centro de pesquisa para desenvolvimento com campo de teste caracteriza-se por atuar sobre as demandas do setor de marketing e propor inovações para o aprimoramento dos produtos.

Tempero do aço para a produção do eixo dos tratores caracteriza-se por uma tecnologia diferenciada desenvolvida pela empresa, que confere durabilidade e confiabilidade dos eixos produzidos e instalados nos tratores da marca.

Logística Integrada entendida como o processo de planejar, implementar e controlar eficientemente, o fluxo e armazenagens de matérias-primas, de todos os estoques e as informações relativas a essas atividades, desde o ponto de origem até o ponto de consumo.

\subsubsection{Associação dos recursos estratégicos com os critérios competitivos da AGCO do Brasil S.A-Canoas}

Verifica-se que os recursos estratégicos podem contribuir para a melhoria do desempenho de todos os critérios "ganhadores de pedidos", que se encontram nas zonas de melhoramento e nas zonas de ação urgente, pela análise da soma das contribuições positivas na Tabela 2 .

A mesma constatação é válida para o critério competitivo "qualificador" (assistência pós-venda),
Observe-se que para os critérios "ganhadores de pedido" os recursos estratégicos da empresa apresentam uma contribuição positiva significativamente maior que as contribuições negativas.

Entretanto, analisando as contribuições negativas, a exemplo da possibilidade de a empresa competir em preço, constata-se um trade-off, pois o recurso centro de pesquisa para o desenvolvimento com campo de teste e o recurso tempero do aço para a produção do eixo dos tratores tanto contribuem para o aprimoramento das demais critérios competitivos quanto prejudicam o critério competitivo "menor custo".

Para que os recursos estratégicos sustentem uma vantagem nestes critérios competitivos, será necessário rever a alocação e a combinação destes recursos dentro da RVO da empresa.

\section{CONSIDERAÇÕES FINAIS}

O framework proposto (Figura 2) mostrou-se importante contribuição para entendimento e análise da priorização dos critérios e seus critérios competitivos. A análise mostrou que um recurso pode contribuir em vários critérios competitivos. Dessa forma, constata-se que não há uma relação direta entre um recurso estratégico específico e um critério competitivo específico. Vários recursos contribuem para um único critério ao mesmo tempo em que um critério necessita de vários recursos, o que significa dizer que para a empresa desenvolver competências em vários critérios há necessidade de 
Tabela 2. Associação dos recursos estratégicos com os critérios competitivos AGCO S.A. - Canoas

\begin{tabular}{|c|c|c|c|c|c|c|c|c|c|c|}
\hline \multirow{3}{*}{$\begin{array}{l} \\
\text { RECURSOS }\end{array}$} & \multicolumn{6}{|c|}{ Ganhadoras de Pedidos } & \multicolumn{4}{|c|}{ Qualificadoras } \\
\hline & \multicolumn{4}{|c|}{$\begin{array}{c}\text { Zona de } \\
\text { Melhoramento }\end{array}$} & \multicolumn{2}{|c|}{$\begin{array}{l}\text { Zona de Ação } \\
\text { Urgente }\end{array}$} & \multicolumn{3}{|c|}{$\begin{array}{c}\text { Zona } \\
\text { Melhoramento }\end{array}$} & \multirow{2}{*}{ 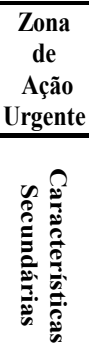 } \\
\hline & 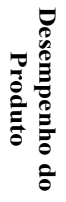 & 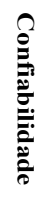 & 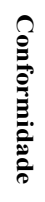 & $\frac{\hat{E}}{\frac{\omega}{\theta}}$ & 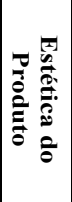 & 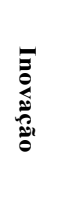 & 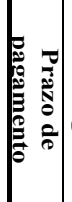 & 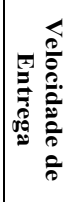 & 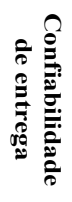 & \\
\hline Transferência de tecnologia entre as unidades & -1 & 1 & -1 & 1 & 1 & 2 & & & & 1 \\
\hline Sistema de controle de qualidade & 1 & 2 & & 1 & & 1 & & & & \\
\hline $\begin{array}{l}\text { Centro de pesquisa para desenvolvimento com } \\
\text { campo de teste }\end{array}$ & 2 & 2 & 1 & -1 & 1 & 2 & & & & \\
\hline $\begin{array}{l}\text { Tempero do aço para a produção do eixo dos } \\
\text { tratores }\end{array}$ & & 1 & & -1 & & & & & & \\
\hline Logística Integrada & & 1 & 1 & 1 & & & 1 & 1 & 1 & \\
\hline Soma das contribuições Positivas & 3 & 7 & 2 & 5 & 2 & 5 & 1 & 1 & 1 & 1 \\
\hline Soma das contribuições Negativas & -1 & & -1 & -2 & & & & & & \\
\hline
\end{tabular}

Fonte: Elaborada pelos autores.

desenvolver vários recursos estratégicos.

O estudo não se ateve aos "porquês" às empresas, mesmo tendo recursos que não desenvolveram competências percebidas pelos clientes, apenas a relação entre os recursos e os critérios. Porém, essa é uma questão a ser estudada. Em relação às empresas, ambas mostraram bons desempenhos em vários critérios competitivos e com possibilidades de melhorarem o desempenho nos critérios ganhadores de pedidos. Especificamente, há trade-offs entre os recursos e os critérios que precisam ser resolvidos. A preocupação central do artigo foi testar o framework e neste sentido recomenda-se novas aplicações em outras situações.

\section{REFERÊNCIAS}

BARNEY, J. B. Resource-based theories of competitive advantage: A ten-year retrospective on the resource-based view. Journal of Management, v.27, n.6, p.643-650. 2001.

BARROS NETO, J. P.; FENSTERSEIFER, J. E. O conteúdo da estratégia de produção: as categorias de decisão da função produção e a construção de edificações. In: Anais do XXIV ENANPAD, ANPAD, Florianópolis-SC, Setembro 2000. CDROM.

FENSTERSEIFER, J. E.; WILK, E. de O. Visão Baseada em Recursos, Clusters e Performance: Um estudo no setor Vitivinícola do RS. In: Anais do XXIX ENANPAD, ANPAD, Brasília, Setembro 2005. CD-ROM.
GRANT, R. M. The Resource-Based Theory of Competitive Advantage: Implications for Strategy Formulation. California Management Review, v.33, n.3, p.114. 1991.

HILL, T. Manufacturing Strategy: text and cases. Burr Ridge, IL: Irwin, 1994.

MALHOTRA, N. Pesquisa de marketing: uma orientação aplicada. Porto Alegre: Bookman, 2001. 719 p.

PAIVA, E. L.; CARVALHO JR., J. M.; FENSTERSEIFER, J. E. Estratégia de Produção e de Operações: conceitos, melhores práticas, visão de futuro. Porto Alegre: Bookman, 2004, 192p.

PIRES, S. Gestão Estratégica da Produção. Piracicaba: Unimep, 1995.

SKINNER, W. Manufacturing: missing link in corporate strategy. Harvard Business Review, Boston, v. 47, n. 3, p. 136145, May/June 1969.

SLACK, N. Vantagem Competitiva em Manufatura. $2^{\text {a }}$ Edição, São Paulo: Atlas, 2002, 198p.

WERNERFELT, Bigger. A Resource-Based View of The Firm. Strategic Management Journal,V. 5, p. 171-180, 1984.

WHEELWRIGHT, S. C. Manufacturing strategy: defining the missing link. Strategic Management Journal, v. 5, n. 1, p. 77-91, Jan./Mar. 1984.

YIN, R. Estudo de caso: planejamento e método. Porto Alegre: Bookman, 2001. 